\title{
Epidemiologia molecular de surto de raiva bovina na região central do Rio Grande do Sul, 2012
}

\author{
Molecular epidemiology of an outbreak of bovine rabies in central Rio Grande do Sul, \\ Brazil, 2012
}

\begin{abstract}
Fábio Adriano Kanitz ${ }^{\mathrm{I}}$ Ananda Paula Kowalski ${ }^{\mathrm{I}}$ Helena Beatriz de Carvalho Ruthner Batista ${ }^{\mathrm{II}}$ Pedro Carnieli Junior ${ }^{\mathrm{II}}$ Rafael de Novaes Oliveira ${ }^{\mathrm{II}}$ Rudi Weiblen ${ }^{\mathrm{I}}$ Eduardo Furtado Flores $^{\text {I* }}$
\end{abstract}

RESUMO

A raiva é uma doença infecciosa do sistema nervoso central de mamíferos causada pelo vírus da raiva (RabV), geralmente, transmitido pela mordedura de animais infectados. No Brasil, os morcegos hematófagos Desmodus rotundus são as principais fontes de infecção do RabV para bovinos e equinos. Este artigo descreve uma investigação epidemiológica e molecular de surtos de raiva ocorridos na região central do Rio Grande do Sul, entre maio e agosto de 2012. Nesse período, 45 casos suspeitos de raiva foram relatados em 22 pequenos rebanhos, localizados dentro de um raio de 4,7km, no município de Pinhal Grande. Desses, 32 amostras foram submetidas para diagnóstico da raiva, sendo que o RabV e/ou antígenos virais foram identificados em 27 amostras. Em um segundo momento, 11 amostras foram submetidas à transcrição reversa/reação em cadeia da polimerase (RT-PCR) para o gene da nucleoproteína (N) do RabV, seguido de sequenciamento nucleotídico e análise filogenética. Sete das 11 amostras apresentaram sequências nucleotídicas idênticas e uma apresentou mutação sinônima, não-codificante, indicando uma provável origem comum dos vírus. Por outro lado, três amostras apresentaram mutações que resultaram em alterações de aminoácidos, sugerindo uma origem diferente do vírus. Esses resultados sugerem que RabV de diferentes origens/linhagens co-circulam na região e foram envolvidos nos surtos descritos. Investigações sobre a circulação de ambos os genótipos em morcegos na região estão em andamento.

Palavras-chave: raiva, Desmodus rotundus, surtos, análise filogenética.

\section{ABSTRACT}

Rabies is an infectious disease of the central nervous system of mammals caused by rabies virus (RabV), generally transmitted by the bite of rabid animals. In Brazil, vampire bats Desmodus rotundus are the main reservoirs of RabV for livestock. The present study describes a molecular and epidemiological investigation of outbreaks of bovine rabies occurring in the central region of Rio Grande do Sul state, Brazil, between May and August 2012. In this period, 45 cases suspected of rabies were reported in 22 small herds, located within a $4.7 \mathrm{~km}$ range, in the county of Pinhal Grande. From these, 32 samples were submitted to rabies diagnosis and RabV and/or viral antigens were identified in 27 samples. Subsequently, 11 brain samples were submitted to reverse transcription/polymerase chain reaction (RT-PCR) for the nucleoprotein gene $(N)$ followed by nucleotide sequencing and phylogenetic analysis. Seven out of 11 samples yielded identical sequences; one presented a synonymous, non-coding mutation, indicating a likely common origin of the virus. However, three other samples presented nucleotide mutations which resulted in amino acid changes, suggesting a different origin of the virus. In summary, these results suggest that RabV strains of different origin/lineages co-circulate in the region and were involved in the outbreaks. Investigations on the circulation of both genotypes in bats in the region are currently underway.

Key words: rabies, Desmodus rotundus, outbreaks, phylogenetic analysis.

\section{INTRODUÇÃO}

A raiva é uma doença infecciosa aguda do sistema nervoso central (SNC) causada pelo vírus da raiva (RabV), pertencente à família $\boldsymbol{R h a b d o v i r i d a e ~}$ e ao gênero Lyssavirus (TORDO et al., 1998). Os vírions do RabV contêm um nucleocapsídeo em forma de projétil recoberto por envelope lipoproteico. O genoma viral é formado por uma cadeia única de ácido ribonucleico (RNA) com polaridade negativa e possui cinco genes, que codificam a nucleoproteína

IDepartamento de Medicina Veterinária Preventiva, Universidade Federal de Santa Maria (UFSM), 97105-900, Av. Roraima, 1000, Santa Maria, RS, Brasil. E-mail: eduardofurtadoflores@gmail.com. *Autor para correspondência.

IIInstituto Pasteur, São Paulo, SP, Brasil. 
(N), a fosfoproteína (P), a glicoproteína (G), a proteína de matriz (M) e a RNA polimerase (L) (ICTV, 2012). Com algumas exceções, particularmente algumas ilhas, o RabV é encontrado em todo o mundo (OIE, 2009). No Brasil, a raiva é endêmica e variantes do RabV têm sido identificadas em cães, canídeos silvestres e saguis, além de morcegos hematófagos e não hematófagos (MOCHIZUKI et al., 2012). Os morcegos hematófagos, especialmente Desmodus rotundus, são os principais reservatórios do RabV na América Latina, sendo os principais transmissores da raiva para os herbívoros (SCHNEIDER et al., 2009).

O sequenciamento parcial do gene da nucleoproteína $(\mathrm{N})$ tem sido utilizado no diagnóstico e em estudos de epidemiologia molecular da raiva, pois esse gene é conservado nos Lyssavirus (BOURHY et al., 2008). Uma divergência na sequência de três aminoácidos no gene $\mathrm{N}$ permite agrupar os isolados brasileiros do RabV em dois grupos: (i) vírus da raiva relacionado aos canídeos e (ii) vírus da raiva relacionada aos morcegos hematófagos (ITO, 2001). Uma análise geográfica e molecular de surtos de raiva bovina na região central e sudeste no Brasil mostrou a relação entre os RabVs identificados nos rebanhos afetados com os vírus de morcegos hematófagos. Com o uso dessas ferramentas, foi possível determinar como o padrão epidemiológico é mantido no tempo e no espaço nessas áreas (KOBAYASHI, 2006). Por meio de análises geográficas e moleculares, também é possível identificar diferentes linhagens do RabV, cujas divergências são influenciadas por características epidemiológicas e ecológicas dos morcegos hematófagos, que, por sua vez, são afetadas pela topografia e geografia da região (KOBAYASHI, 2008).

Historicamente, a raiva tem causado importantes perdas a rebanhos bovinos em várias regiões do País, acarretando um impacto econômico negativo à cadeia produtiva (SCHNEIDER et al., 2009). Durante o ano de 2012, foram notificados oficialmente no Brasil 1435 casos de raiva em bovinos, contabilizando-se somente aqueles diagnosticados em laboratórios oficiais e credenciados (MAPA, 2013). No entanto, dados da Secretaria de Agricultura do Rio Grande do Sul (RS) indicam a ocorrência de aproximadamente quatro mil casos de raiva bovina entre janeiro e junho de 2013 (SEAPA, 2013).

Acompanhando essa tendência, entre maio e agosto de 2012, foram relatados 45 casos suspeitos de raiva em 22 rebanhos bovinos no município de Pinhal Grande, região central do RS. Destes, 32 amostras foram submetidas ao diagnóstico e 27 foram diagnosticadas positivas para a raiva. O objetivo do presente trabalho foi descrever esses eventos, procurando identificar e caracterizar geneticamente os RabVs envolvidos.

\section{MATERIAL E MÉTODOS}

Foram testadas 32 amostras de bovinos, oriundas de casos ocorridos no município de Pinhal Grande (latitude: 29²0'46”S e longitude: 53¹8’24”W), região central do Rio Grande do Sul, entre maio e agosto de 2012. O diagnóstico laboratorial foi realizado em fragmentos do encéfalo (hipocampo, cerebelo e córtex), utilizando-se os dois testes-padrão de diagnóstico da raiva: imunofluorescência direta (IFD) e inoculação intracerebral em camundongos (MIT, OIE, 2009). O material foi enviado por Médicos Veterinários autônomos ou do quadro da Secretaria de Agricultura do RS, acompanhado de histórico clínico e epidemiológico. Os locais de origem das amostras e a localização de furnas catalogadas pela Secretaria de Agricultura do Estado do RS, que abrigam colônias de morcegos hematófagos, foram obtidos pelo sistema de posicionamento global (GPS) e plotados no mapa da região.

Após a confirmação do diagnóstico, os materiais positivos foram encaminhados ao Instituto Pasteur(São Paulo, SP) para análise molecular. Paratal, foi realizada a extração de RNA total dos fragmentos, utilizando-se o reagente Trizol (Invitrogen Life Tecnologies $^{\mathrm{TM}}$ ). Posteriormente, o RNA extraído foi submetido à transcrição reversa, seguida da reação em cadeia pela polimerase (RT-PCR) para amplificação do gene que codifica a nucleoproteína $\mathrm{N}$ do RabV (CARNIELI, 2005), com os seguintes primers: 21G (senso, 5'ATGTAACACCTCTACAATG3') e 304 (antisenso, 5' TTDACGAAGATCTTGCTCAT3'), descritos por ORCIARI et al. (2001). Os amplicons foram purificados com o kit GFX ${ }^{T M}$ PCR DNA and Gel Band Purification kit (GE Healthcare ${ }^{\mathrm{TM}}$ ) e submetidos ao sequenciamento genético. A reação de sequenciamento de DNA foi realizada com 3,2pmol de cada primer (senso- $21 \mathrm{G}$ e antisenso- 304), descritos anteriormente e com BigDye Terminator v3.1 Cycle Sequencing Kit (Applied Biosystems ${ }^{\circledR}$ ). Para obtenção das sequências nucleotídicas, foi utilizado o analisador genético automático 3130 da Applied Biosystems $^{\circledR}$. Foram analisados 1218 nucleotídeos da região codificante da proteína $\mathrm{N}$, localizados entre os nucleotídeos 203 e 1421 da amostra PV, padrão de RabV (acesso M13215.1). As sequências foram editadas usando o software CHROMAS (versão 2.24 Copyright 1998-2004 Technelysium Pty Ltd.), alinhadas pelo método CLUSTAL/W (versão 7.1.3.0 do software BIOEDIT, HALL, 1999) e utilizadas para 
aferir a identidade das espécies, utilizando o Basic Local Alignment Search Tool (BLAST). Uma árvore filogenética para determinar e confirmar as relações evolutivas entre as espécies foi construída com o software MEGA (versão 5.0), usando o método maximum likelyhood com o modelo de substituição GTR (G + I) 5.0 (TAMURA, et al., 2011) e a confiabilidade foi avaliada com bootstrap de 1.000 repetições. Os cálculos de diversidade e identidade intragrupo entre as amostras sequenciadas neste trabalho foram realizados com o software MEGA (versão 5.0).

\section{RESULTADOS}

Os casos descritos neste estudo ocorreram entre final de maio e agosto de 2012, abrangendo um intervalo um pouco inferior a três meses. Quarenta e cinco animais, oriundos de 22 rebanhos, apresentaram sinais neurológicos sugestivos de raiva (perda do trem posterior, ataxia, incoordenação e decúbito esternal) e foram a óbito. Os rebanhos acometidos pertenciam a pequenas propriedades, caracterizadas pela produção diversificada e agricultura de subsistência, e possuíam entre dois e 58 animais com aptidão para carne e também bovinos leiteiros (Tabela 1).

Os focos concentraram-se dentro de um raio de 4,7 quilômetros (km) (Figura 1), todos com proximidade do Rio Jacuí, sendo que a propriedade mais distante é localizada a 7,2km da margem. Dentro dos limites do surto, situam-se duas furnas (F1 com latitude: 29¹7’57.07’'S e longitude: 53¹5'27.94”O; e F2 com latitude: 29¹9'44.13”'S e longitude: 53¹4’31.88”O) cadastradas pela Secretaria de Agricultura do RS, locais em que técnicos realizam vistorias e ações periódicas de combate a morcegos hematófagos.

Das 32 amostras enviadas, 27 foram positivas para o RabV pelos testes de IFD e/ ou inoculação em camundongos (MIT). O sequenciamento de 1218 nucleotídeos do gene $\mathrm{N}$ de 11 dessas amostras demonstrou sequências características da linhagem do RabV de morcegos hematófagos Desmodus rotundus. Sete destas amostras (SV 229/12, SV 256/12, SV 275/12, SV 276/12, SV 335/12, SV 362/12 e SV 528/12) apresentaram sequências nucleotídicas idênticas entre si (100\% de identidade). Uma amostra (SV 447/12) apresentou uma mutação sinônima no nucleotídeo 141 [codificante de aminoácido (aa) de mesmo grupo químico]. Outras três amostras (SV 214/12, SV 336/12 e SV 529/12) apresentaram mutações não sinônimas. Destas, as amostras SV 214/12 e SV 336/12 apresentaram a mesma mutação (posição 1243, troca do aa ácido glutâmico [E] pelo aa aspartato [D]). Já a amostra SV 529/12 apresentou

Tabela 1 - Identificação das propriedades, data, localização geográfica e número de animais afetados.

\begin{tabular}{|c|c|c|c|c|c|}
\hline Identificação da amostra & Propriedade & Data & Posicionamento Geográfico & $\begin{array}{l}\text { Número de bovinos } \\
\text { acometidos }\end{array}$ & $\begin{array}{l}\text { Número de bovinos na } \\
\text { propriedade }\end{array}$ \\
\hline SV $214 / 12$ & A & $28 / 5$ & $29^{\circ} 17^{\prime} 25.60^{\prime \prime S} 53^{\circ} 15^{\prime} 48.70^{\prime O}$ & 2 & 38 \\
\hline SV 229/12 & B & $30 / 5$ & $29^{\circ} 18^{\prime} 48.40^{\prime S} 53^{\circ} 15^{\prime} 29.10^{\prime O}$ & 1 & 15 \\
\hline SV $230 / 12$ & $\mathrm{C}$ & $30 / 5$ & $29^{\circ} 19^{\prime} 30.50^{\prime \prime S} 53^{\circ} 16^{\prime} 17.10^{\prime O}$ & 3 & 20 \\
\hline SV 253/12 & $\mathrm{D}$ & $4 / 6$ & $29^{\circ} 19^{\prime} 30.50^{\prime \prime S} 53^{\circ} 16^{\prime} 17.10^{\prime \prime O}$ & 4 & 54 \\
\hline SV 256/12 & $\mathrm{E}$ & $4 / 6$ & $29^{\circ} 20^{\prime} 27.50^{\prime \prime S} 53^{\circ} 17^{\prime} 58.00^{\prime \prime O}$ & 1 & 2 \\
\hline SV $257 / 12$ & $\mathrm{~F}$ & $4 / 6$ & $29^{\circ} 19^{\prime} 6.40^{\prime S} 53^{\circ} 16^{\prime} 40.20^{\prime \prime O}$ & 3 & 43 \\
\hline SV $274 / 12$ & G & $12 / 6$ & $29^{\circ} 18^{\prime} 42.90^{\prime \prime S} 53^{\circ} 15^{\prime} 14.40^{\prime \prime O}$ & 3 & 31 \\
\hline SV $275 / 12$ & $\mathrm{H}$ & $12 / 6$ & $29^{\circ} 18^{\prime} 42.80^{\prime \prime S} 53^{\circ} 15^{\prime} 13.50^{\prime \prime O}$ & 2 & 28 \\
\hline SV 276/12 & I & $12 / 6$ & $29^{\circ} 18^{\prime} 42.80^{\prime \prime S} 53^{\circ} 15^{\prime} 13.50^{\prime \prime O}$ & 1 & 58 \\
\hline SV $277 / 12$ & $\mathrm{~J}$ & $12 / 6$ & 29॰19'30.60"S 53¹4'19.30"O & 3 & 20 \\
\hline SV 298/12 & $\mathrm{L}$ & $18 / 6$ & $29^{\circ} 17^{\prime} 59.20^{\prime \prime S} 53^{\circ} 16^{\prime} 55.20^{\prime \prime O}$ & 2 & 25 \\
\hline SV 329/12 & M & $26 / 6$ & 29¹9'29.10"S 53¹8'59.30"O & 1 & 44 \\
\hline SV 330/12 & $\mathrm{N}$ & $26 / 6$ & $29^{\circ} 17^{\prime} 24.20^{\prime \prime S} 53^{\circ} 15^{\prime} 42.90^{\prime \prime O}$ & 4 & 26 \\
\hline SV 334/12 & $\mathrm{O}$ & $29 / 6$ & $29^{\circ} 19^{\prime} 21.00^{\prime \prime S} 53^{\circ} 17^{\prime} 44.10^{\prime \prime O}$ & 2 & 40 \\
\hline SV 335/12 & $\mathrm{P}$ & $29 / 6$ & $29^{\circ} 19^{\prime} 10.60^{\prime \prime S} 53^{\circ} 17^{\prime} 43.90^{\prime \prime O}$ & 3 & 62 \\
\hline SV 336/12 & Q & $29 / 6$ & $29^{\circ} 17^{\prime} 59.20^{\prime \prime S} 53^{\circ} 16^{\prime} 55.20^{\prime \prime O}$ & 3 & 54 \\
\hline SV 362/12 & $\mathrm{R}$ & $03 / 7$ & $29^{\circ} 17^{\prime} 59.20^{\prime \prime S} 53^{\circ} 16^{\prime} 55.20^{\prime \prime O}$ & 1 & 31 \\
\hline SV $446 / 12$ & $\mathrm{~S}$ & $06 / 8$ & $29^{\circ} 22^{\prime} 50.30^{\prime \prime S} 53^{\circ} 15^{\prime} 80.50^{\prime \prime O}$ & 2 & 18 \\
\hline SV $447 / 12$ & $\mathrm{~T}$ & $06 / 8$ & $29^{\circ} 19^{\prime} 40.20^{\prime \prime S} 53^{\circ} 15^{\prime} 57.40^{\prime \prime O}$ & 1 & 7 \\
\hline SV 528/12 & $\mathrm{U}$ & $23 / 8$ & $29^{\circ} 18^{\prime} 27.30^{\prime \prime S} 53^{\circ} 15^{\prime} 40.70^{\prime \prime O}$ & 2 & 34 \\
\hline SV 529/12 & $\mathrm{V}$ & $23 / 8$ & $29^{\circ} 19^{\prime} 49.20^{\prime \prime S} 53^{\circ} 17^{\prime} 57.40^{\prime \prime O}$ & 1 & 25 \\
\hline
\end{tabular}




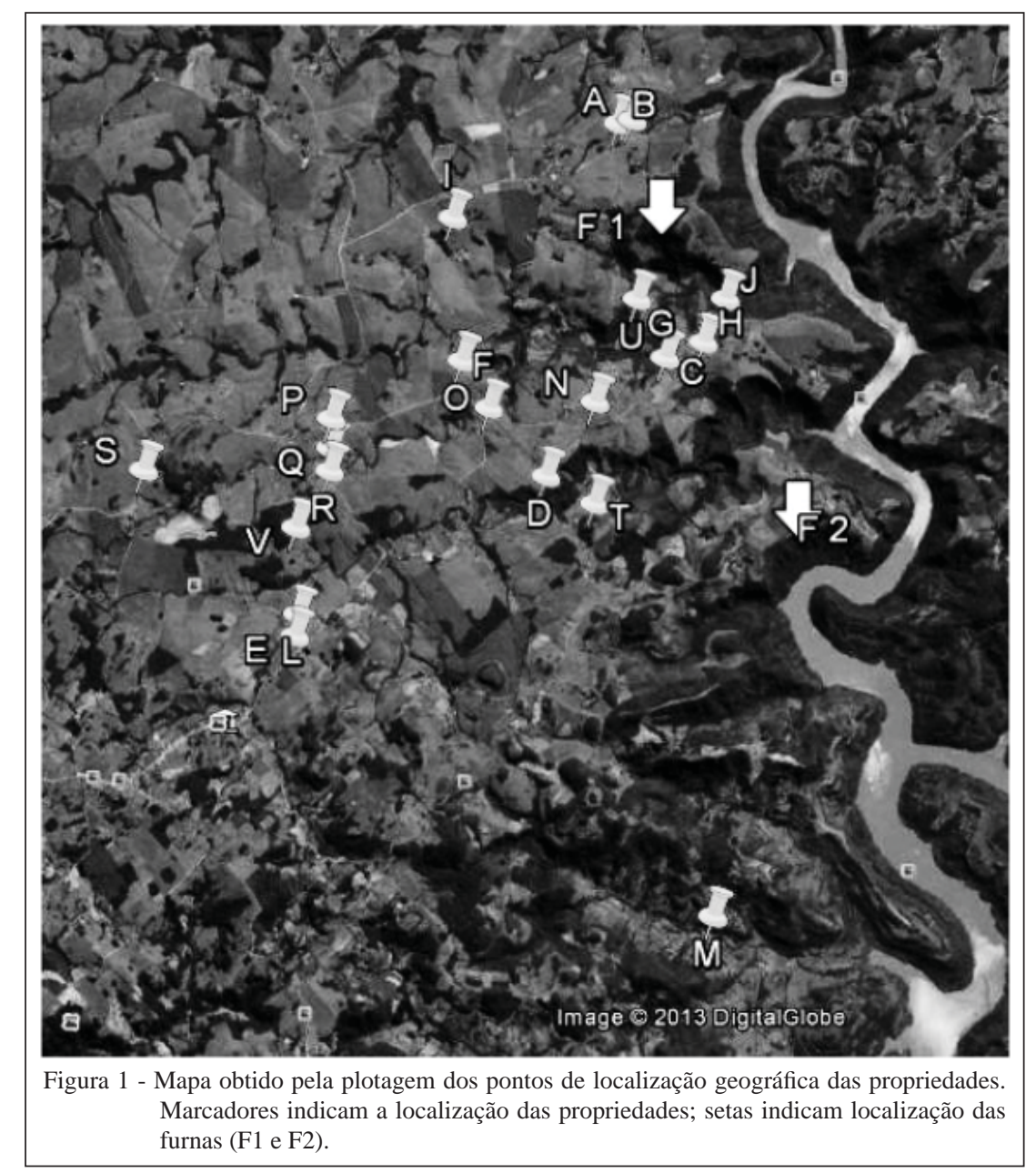

troca do aa asparagina $(\mathrm{N})$ pelo aa serina (S), na posição 219.

A topologia da árvore filogenética (Figura 2) pode ser dividida em três agrupamentos: de morcegos hematófagos, de morcegos nãohematófagos e de caninos. Todas as amostras sequenciadas localizaram-se no agrupamento de morcegos hematófagos e formaram três subgrupos: subgrupo 1 (amostra SV 529/12); subgrupo 2 (SV 214/12 e SV 336/12); e subgrupo 3, formado pelas demais amostras idênticas entre si. A diversidade entre as amostras sequenciadas foi de $0,2 \%$. A identidade entre as amostras correspondente a cada um dos subgrupos foi de 1,1\% entre os subgrupos 1 e 2, $1 \%$ entre os subgrupos 2 e 3 e finalmente de $0,1 \%$ entre os subgrupos 1 e 3 .

\section{DISCUSSÃO}

No Brasil, a raiva apresenta diferentes níveis de endemicidade de acordo com a região. No
Rio Grande do Sul, a raiva urbana, que é transmitida por cães domésticos, está erradicada desde 1988 (BATISTA et al., 2007). Já a raiva dos herbívoros, transmitida por morcegos hematófagos Desmodus rotundus, continua endêmica, sendo, que em 2012 e 2013, foi registrada a maior incidência de casos desde a década de 80 . O presente estudo descreve um surto de raiva bovina ocorrido no final do outono e inverno, abrangendo 22 propriedades na região central do Rio Grande do Sul, onde foram identificadas 27 amostras positivas para o RabV. Dentre as 32 amostras analisadas, 27 resultaram positivas. Esse número revela-se atípico quando comparado com a casuística observada no Setor de Virologia da UFSM no período de 2001 a 2011, quando foram examinadas 96 amostras suspeitas e 31 resultaram positivas. Ou seja, o presente surto resultou em número de positivos equivalente ao total diagnosticado no SV/UFSM nos 10 anos anteriores.

Além da área central do Rio Grande do Sul, outras regiões apresentaram um crescimento no

Ciência Rural, v.44, n.5, mai, 2014. 


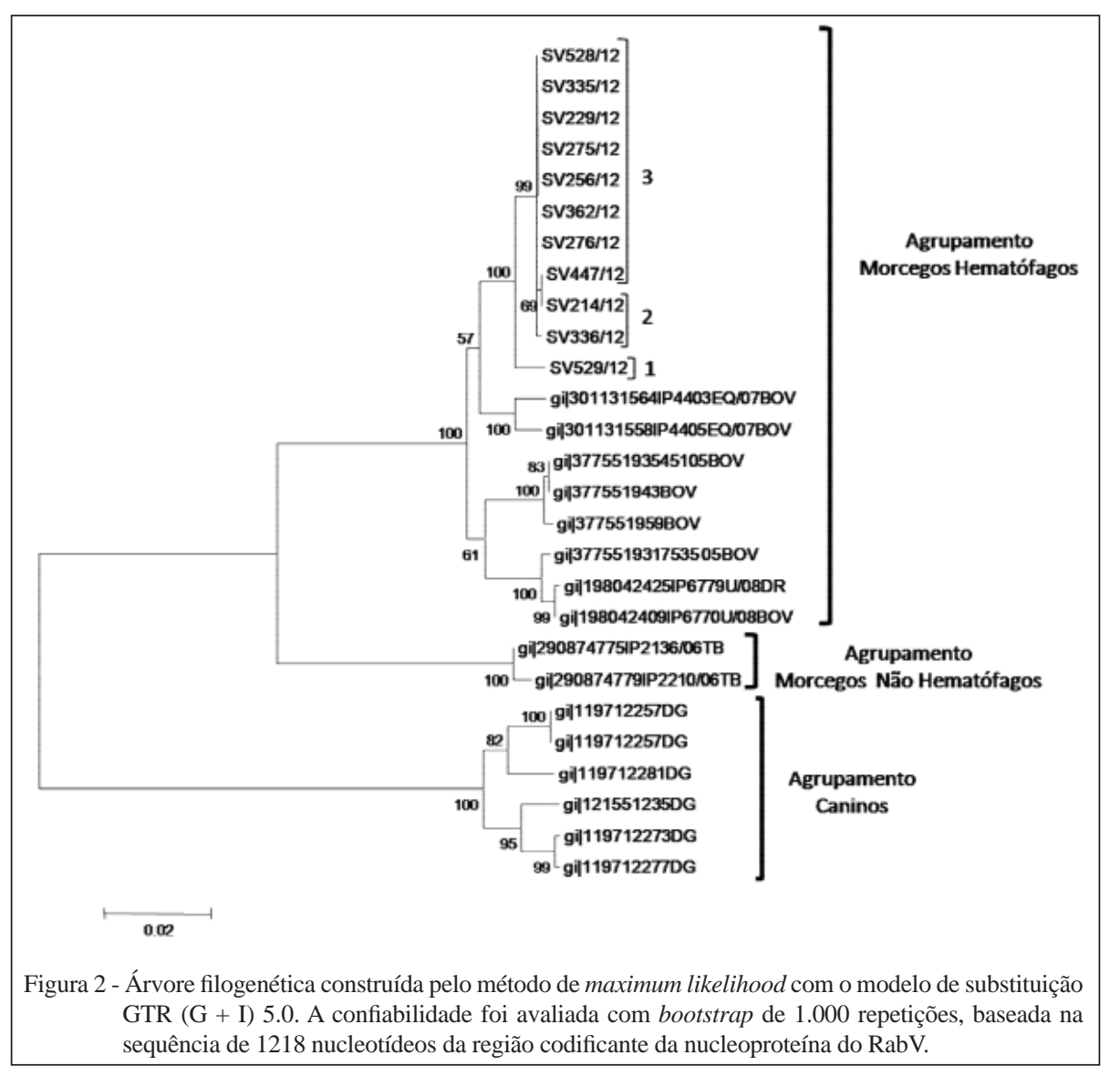

número de casos de raiva bovina nos últimos anos. Entre os meses de janeiro e junho de 2013, cerca de quatro mil bovinos morreram em decorrência de raiva. Somando-se os dados de 2011 a 2013, esse número se aproxima dos 30 mil (SEAPA, 2013). Somente em perdas diretas, os prejuízos estão estimados em 30 a 40 milhões de reais. Eventos como este podem estar relacionados a um aumento na população de morcegos hematófagos (LORD, 1988) e também a fatores ambientais, além da oferta de alimento (LEE, 2012). Os casos descritos neste estudo ocorreram após um longo período de estiagem no RS (2010-2011), em que a região central do Estado passou pelo maior período de seca dos últimos 60 anos (AGRICULTURA, 2012). Outros fatores, como a alta densidade populacional de bovinos na região e a pequena distância entre as furnas/ abrigos e os rebanhos podem também ter contribuído para esses casos (GOMES et al., 2010). É possível que a longa estiagem, somada ao desmatamento e à ocupação desordenada de áreas antes preservadas, tenham gerado mudanças ambientais que resultaram em um aumento na população de morcegos hematófagos e, consequentemente, no grande número de casos de raiva observado.
Em nível de Estado, além do aumento explosivo do número de casos, a ocorrência de raiva tem se expandido geograficamente, passando a afetar áreas até então indenes (ou hipoendêmicas), como a fronteira oeste e região da campanha (SEAPA, 2013). As causas dessa expansão são desconhecidas até o presente, mas provavelmente envolvem questões ecológico-ambientais que afetam a biologia e comportamento dos quirópteros. Diante desse aumento na incidência de raiva em bovinos no RS, as atuais recomendações para o controle da doença no Estado deveriam ser revisadas.

As propriedades foco concentraram-se dentro de um raio de $4,7 \mathrm{~km}$ e possuem proximidade com o Rio Jacuí. Dentro dos limites geográficos do surto, também existem duas furnas catalogadas pelo serviço de combate a morcegos hematófagos da Secretaria de Agricultura do RS. Tais distâncias estão dentro do raio de vôo dos Desmodus rotundus, que geralmente buscam alimento dentro de um raio de 2 a $7 \mathrm{~km}$ do seu abrigo (ARELLANO, 1988). Além disso, condições climáticas favoráveis, presença de abrigos naturais (furnas, matas) ou artificiais e presença 
de bovinos contribuem para a ocorrência da raiva (BARROS et al., 2006).

As diferenças de nucleotídeos apresentadas pelas amostras analisadas são pouco significantes. Sendo assim, sugere-se que as oito amostras (sete idênticas entre si e uma com alteração de um nucleotídeo) tenham origem comum, ou seja, sejam originadas de um mesmo vírus ou sublinhagem viral. Por outro lado, as amostras que contêm mutação com alteração de aminoácido (SV 214/12, SV 336/12 e SV 529/12) possivelmente pertençam a outra sublinhagem, indicando a circulação de mais de uma linhagem do RabV na região.

A identificação de três subgrupos da linhagem genética de RabV de morcegos hematófagos Desmodus rotundus indica a co-circulação dessas sublinhagens na região. Essas linhagens podem ter origem em três colônias de morcegos (cada uma mantendo uma sublinhagem) ou, eventualmente, a manutenção de mais de uma sublinhagem do vírus em uma mesma colônia. A identificação de três sublinhagens do RabV pode ainda ser reflexo de mutações totalmente aleatórias, características de vírus com genoma RNA. Para o conjunto de amostras analisadas, é difícil confirmar ou refutar essas hipóteses, principalmente pelo fato de a análise ter se restringido a amostras obtidas do hospedeiro terminal, os bovinos.

\section{CONCLUSÃO}

Três sublinhagens do RabV de Desmodus rotundus foram identificadas nos surtos ocorridos na região central do RS, em 2012.

\section{REFERÊNCIAS}

AGRICULTURA. Notícias da agricultura. Canal rural, Porto Alegre, 23 mar. 2012. Especiais. Acesso em: 14 dez. 2012. Online. Disponível em: <http://agricultura.ruralbr.com.br/noticia/2012/11/ encontro-no-rio-grande-do-sul-debate-propostas-de-prevencao-aseca-3966719.html>.

ARELLANO, C. Biology, ecology and control of the vampire bat. Reviews of Infectious Diseases, v.10, p.615-619, 1988. Disponível em: <http://cid.oxfordjournals.org/content/10/Supplement_4/S615. full.pdf+html>. Acesso em: 25 jun. 2013.

BARROS, C.S.L. et al. Doenças do sistema nervoso de bovinos no Brasil. São Paulo: Vallée, 2006. p.21-28.

BATISTA, H.B.C.R. et al. Rabies: a brief review. Acta Scientiae Veterinariae, v.35, p.125-144, 2007.

BOURHY, H. et. al. The origin and phylogeography of dog rabies virus. Journal of General Virology, v.89, p.2673, 2008. Disponível em: <http://vir.sgmjournals.org/content/89/11/2673.full.pdf+html>. Acesso em: 25 jun.2013. doi: 10.1099/vir.0.2008/003913-0.
CARNIELI, P.J. et al. Phylogeny of a rabies virus identified in a cat closely related to vampire bat rabies based on the nucleoprotein gene. Virus Reviews and Research, v.10, p.50-54, 2005.

GOMES, M.N. et al. Landscape risk factors for attacks of vampire bats on cattle in São Paulo, Brazil. Preventive Veterinary Medicine, v.93, p.139-146, 2010. Disponível em:<http://ac.els-cdn.com/S $0167587709003134 / 1$ s2.0-S0167587709003134-main.pdf?_tid=b9891bd4fba6-11e2-b70b-00000aacb362\&acdnat $=1375470607$ _ af445bffae2c562387c6dde5cd5eae8a>. Acessao em: 20 jul. 2013.

HALL, T.A. BioEdit: a user-friendly biological sequence alignment editor and analysis program for Windows 95/98/NT. Nucleic Acids Symposium Series, v.41, p.95-98, 1999.

ITO, M. et al. Genetic characterization and geographic distribution of rabies virus isolates in Brazil: identification of two reservoirs, dogs and vampire bats. Virology, v.284, p.214-222, 2001. Disponível em: <http:/www.sciencedirect.com/science/article/pii/ S0042682200909164\#>. Acesso em: 25 jun.2013. doi: 10.1006/ viro.2000.0916.

ICTV (INTERNATIONAL COMMITTEE ON TAXONOMY OF VIRUSES), 2012. Acesso em: 25 jun. 2013. Online. Disponível em: <http://www.ncbi.nlm.nih.gov/ICTVdb/Ictv/index.htm>.

KOBAYASHI, Y. et. al. Geographical distribution of vampire batrelated cattle rabies in Brazil. Journal of Veterinary Medical Science, v.68, p.1097-1100, 2006. Disponível em: <http://www. ncbi.nlm.nih.gov/pubmed/17085890>. Acesso em: 26 jun.2013.

KOBAYASHI, Y. et. al. Molecular and geographic analyses of vampire bat-transmitted cattle rabies in central Brazil. BMC Research Notes, v.4, p.1-9, 2008. Disponível em: <http://www. biomedcentral.com/content/pdf/1746-6148-4-44.pdf>. Acesso em: 25 jun.2013. doi: 10.1186/1746-6148-4-44.

LEE, D.N. et al. Present and potential future distribution of common vampire bats in the Americas and the associated risk to cattle. PLoS ONE, v.7, p.1-9, 2012. Disponível em: <http://www.plosone.org/ article/info\%3Adoi\%2F10.1371\%2Fjournal.pone.0042466?utm_ source=feedburner\&utm_medium=feed \&utm_campaign=Fee $\mathrm{d} \% 3 \mathrm{~A}+$ plosone $\% 2 \mathrm{FComputationalBiology}+(\mathrm{PLoS}+\mathrm{ONE}+\mathrm{Ale}$ rts\%3A+Computational+Biology)>. Acesso em: 14 jun.2013. doi:10.1371/journal.pone.0042466.

LORD, R.D. et al. Control of vampire bats. In: GREENHALL A.M. \& SCHMIDT, U. Natural history of vampire bats. Florida: CRC, 1988. p.215-226.

MAPA (MINISTÉRIO DA AGRICULTURA PECUÁRIA E ABASTECIMENTO), 2013. Disponível em: <http://www. agricultura.gov.br/arq_editor/file/Aniamal/programa\%20 nacional\%20dos\%20herbivoros/Dados\%20controle\%20 raiiva\%20herb\%C3\%ADvoros\%20Brasil\%20ate\%202012.pdf>. Acesso em: 24 jul.2013.

MOCHIZUKI, N. et al. Molecular epidemiology of livestock rabies viruses isolated in the northeastern Brazilian states of Paraíba and Pernambuco from 2003 - 2009. BMC Research Notes, v.5, p.32, 2012. Disponível em: <http://www.biomedcentral.com/17560500/5/32>. Acesso em: 26 jun.2013. doi:10.1186/1756-0500-5-32.

OIE. Rabies. World Organisation for Animal Health. Technical Disease Card, 2009. Disponível em: <http://www.oie.int/ 
fileadmin/Home/eng/Publications_\%26_Documentation/docs/pdf/ rabies.pdf>. Acesso em: 04 jun.2013.

ORCIARI, L.A. et al. Rapid clearance of SAG-2 rabies virus from dogs after oral vaccination. Vaccine, v.19, n.31, p.4511-4518, 2001. Disponível em: <http://ac.els-cdn.com/S0264410X01001864/1s2.0-S0264410X01001864-main.pdf?_tid=62b67644-1d34-11e3949f-00000aab0f6b\&acdnat=1379159838_6657ad7d163d9ddce0 638ea93aa17c17>. Acesso em: 14 jul. 2013.

SCHNEIDER, M.C. et al. Rabies transmitted by vampire bats to humans: an emerging zoonotic disease in Latin America?. Revista Panamericana de Salud Pública, v.25, p.260-269, 2009. Disponível em: <http://www.biomedcentral.com/content/ pdf/1756-0500-5-32.pdf>. Acesso em: 25 jun. 2013.
SEAPA. Noticias. Assessoria de Imprensa. Secretaria da Agricultura Pecuária e Agronegócio, Porto Alegre, 21 jun. 2013. Acesso em: 20 jul. 2013. Online. Disponível em: <http://www. agricultura.rs.gov.br/conteudo/4270/?Raiva_j\%C3\%A1_matou_ quatro_mil_animais_no_Estado_em_2013>.

TAMURA, K. et al. MEGA5: Molecular Evolutionary Genetics Analysis Using Maximum Likelihood, Evolutionary Distance, and Maximum Parsimony Methods. Molecular Biology and Evolution. v. 4, p.1-9, 2011.

TORDO, N. et al. Rhabdoviruses: rabies. In: Hodder Education Publishers. Topley and Wilson's microbiology and microbial infections. Londres, 1998. p.666-692. 